Check for updates

Cite this: RSC Adv., 2018, 8, 3951

Received 7th October 2017

Accepted 10th January 2018

DOI: 10.1039/c7ra11049a

rsc.li/rsc-advances

\section{Mechanism of iodine release from iodoapatite in aqueous solution}

\author{
Z. Zhang, (D) a A. Heath, ${ }^{b}$ K. T. Valsaraj, ${ }^{\text {b W. L. Ebert, }}{ }^{c}$ T. Yao, ${ }^{d}$ J. Lian (D) ${ }^{d}$ \\ and J. Wang (D) *a
}

Safe disposal of nuclear waste is essential to ensure the sustainability of nuclear energy. This is especially true for the volatile radionuclide iodine-129 due to its long half-life (15.7 Ma) and high mobility in most disposal environments. The dissolution behaviour of lead vanadium iodoapatite $\left(\mathrm{Pb}_{5}\left(\mathrm{VO}_{4}\right)_{3} \mathrm{l}\right)$ synthesized to evaluate its possible use for immobilizing iodine-129 was investigated to understand the mechanism by which iodide is released. Experiments using a semi-dynamic method were carried out in cap-sealed Teflon vessels at a constant temperature $90 \pm 0.5{ }^{\circ} \mathrm{C}$ with a fixed sample surface area-to-solution volume ratio of $16 \mathrm{~m}^{-1}$. The leachates were analyzed using inductively coupled plasma mass spectrometry (ICP-MS) and the leached surfaces were examined by X-ray diffraction (XRD), scanning electron microscopy (SEM) and infrared spectroscopy (IR). The results show that lead and vanadium dissolved congruently at a constant rate, while the iodine was initially released at a significantly higher rate than suggested by its stoichiometry with respect to lead and vanadium. The iodine-to-lead molar ratio in the solution gradually decreased over time, but iodine release remained superstoichiometric. The results suggest the release of iodide occurs by an ion-exchange process that is faster than the dissolution rate of the $\mathrm{Pb}-\mathrm{V}-\mathrm{O}$ framework. Analysis of the leached samples shows that the spectroscopic signature of $\mathrm{OH}$ groups in the leached samples is consistent with an ion exchange mechanism.

\section{Introduction}

Safe disposal of radionuclides generated from nuclear fission is important in the sustainable development and public acceptance of nuclear energy. Among the large number of fission products in nuclear waste, iodine- 129 is a primary dose contributor considered in disposal safety analyses because of its long half-life ( $\sim 15.7$ million years) and weak sorption to engineering barriers and rocks in geological formations being considered for disposal facilities. Iodine cannot be efficiently incorporated into the borosilicate glasses developed to immobilize high-level nuclear waste by a vitrification process $^{1,2}$ due to its low solubility and volatile nature. ${ }^{3,4}$ Therefore, other durable waste forms need to be developed to immobilize iodine- 129 for disposal. In addition, iodine release behaviour from these waste forms in disposal environments needs to be established to predict their long-term performance. Decades of research have developed a collection of waste forms: glass, ceramics, glass

\footnotetext{
${ }^{a}$ Department of Geology and Geophysics, Louisiana State University, Baton Rouge, Louisiana 70803, USA.E-mail:jianwei@lsu.edu

${ }^{b}$ Department of Chemical Engineering, Louisiana State University, Baton Rouge, Louisiana 70803, USA

${ }^{c}$ Nuclear Engineering, Argonne National Lab, Lemont, Illinois 60439, USA

${ }^{d}$ Department of Mechanical and Nuclear Engineering, Rensselaer Polytechnic Institute,

Troy, New York 12180, USA
}

ceramics, cement, and composite materials. ${ }^{5}$ Many of those waste forms are promising for iodine incorporation or encapsulation with favourable thermal, mechanical, and chemical stability. However, there is a lack of understanding regarding their durability relative to the regulatory time frame of hundreds of thousands years. To predict its long-term release behaviour in geological disposal environments, it is essential to understand iodine release mechanism and the effects of the environmental variables on the dissolution behaviour of the host material under expected disposal conditions. This requires a systematic study of the waste form degradation behaviour.

Among the waste forms being evaluated, single phase ceramic iodoapatite $\mathrm{Pb}_{5}\left(\mathrm{VO}_{4}\right)_{3} \mathrm{I}$ has been proposed as a waste form for iodine-129,,$^{6-18}$ and is simpler than multiphase waste forms ${ }^{5}$ in terms of phase complexity, microstructure, and composition, which are a great challenge to evaluate their chemical durability because of the complications from their complexity. In the iodoapatite structure, $\mathrm{Pb}$ cations occupy two crystallographic sites with 8 and 9 coordination numbers and $\mathrm{V}$ forms tetrahedra with oxygen. Together, $\mathrm{VO}_{4}$ and $\mathrm{Pb}$ sites form a more covalently bonded framework structure while the iodide anions, at the channel site in the crystal structure, are more ionically bonded to the cations due to a smaller ionic potential (charge to radius ratio) than the lead ion. ${ }^{19}$ 
The results of previous durability tests with iodoapatite vary significantly..$^{\mathbf{9} 17,20-22}$ For instance, a durability study was conducted in deionized water at $90{ }^{\circ} \mathrm{C}$ for iodoapatite $\left(\mathrm{Pb}_{10}\left(\mathrm{VO}_{4}\right)_{4.8}\left(\mathrm{PO}_{4}\right)_{1.2} \mathrm{I}_{2}\right)$ synthesized with a hot press method at $25 \mathrm{MPa}$ and $700{ }^{\circ} \mathrm{C}$ using a flow through method..$^{20}$ The initial iodine leaching rate was high but gradually decreased to a rate of $2.5 \times 10^{-3} \mathrm{~g} \mathrm{~m}^{-2} \mathrm{~d}^{-1}$ after 2 weeks in a 38 day experiment. In another experiment, an iodoapatite sample with a composition $\mathrm{Pb}_{10}\left(\mathrm{VO}_{4}\right)_{4.8}\left(\mathrm{PO}_{4}\right)_{1.2} \mathrm{I}_{2}$ synthesized at similar conditions ${ }^{9}$ was studied using a static test method. ${ }^{23}$ The initial release rate in pure water was $2.4 \times 10^{-3} \mathrm{~g} \mathrm{~m}^{-2} \mathrm{~d}^{-1}$ at $90{ }^{\circ} \mathrm{C}$, ${ }^{9}$ which makes iodoapatite a promising candidate as an iodine waste form. The low release rate was speculated to be caused by surface layers or secondary phases. Recently, a durability study using static leaching experiment was carried out to examine iodoapatite $\mathrm{Pb}_{5}\left(\mathrm{VO}_{4}\right)_{3} \mathrm{I}$ that was synthesized using a dry mechanochemical process at $400{ }^{\circ} \mathrm{C}^{21}$ The iodine release rate in pure water at $25^{\circ} \mathrm{C}$ and surface area-to-solution volume ratio $(\mathrm{S} / \mathrm{V})$ of $1.0 \mathrm{~m}^{-1}$ was $2.6 \times 10^{-1} \mathrm{~g} \mathrm{~m}^{-2} \mathrm{~d}^{-1}$ on the first day and reduced to $8.8 \times 10^{-3} \mathrm{~g} \mathrm{~m}^{-2} \mathrm{~d}^{-1}$ after 56 days of experiments, which is still much higher than the value of $1.7 \times 10^{-4} \mathrm{~g} \mathrm{~m}^{-2} \mathrm{~d}^{-1}$ measured by Guy et al. in a similar static leaching experiment. ${ }^{9}$ The result leads to the question whether or not sufficient protecting layers were formed in the leaching experiment. More recently, an iodate $\left(\mathrm{IO}_{3}{ }^{-}\right)$variation of iodoapatite, $\mathrm{Ca}_{10}\left(\mathrm{PO}_{4}\right)_{6}\left(\mathrm{IO}_{3}\right)_{0.92}(\mathrm{OH})_{1.08}$, was proposed to incorporate iodine into hydroxyapatite by substituting $\mathrm{OH}^{-}$groups with $\mathrm{IO}_{3}{ }^{-}$in hydroxyapatite. ${ }^{13,17}$ The sample was tested using static leaching experiment at $50{ }^{\circ} \mathrm{C}$ in deionized water, ${ }^{24}$ which gave an initial release rate of iodine $2 \times 10^{-2} \mathrm{~g} \mathrm{~m}^{-2} \mathrm{~d}^{-1}$ and a residual rate of $7 \times 10^{-5} \mathrm{~g} \mathrm{~m}^{-2} \mathrm{~d}^{-1}$, with a $\mathrm{S} / \mathrm{V}$ ratio of $800 \mathrm{~m}^{-1}$ and $8000 \mathrm{~m}^{-1}$ respectively. As seen from the above experimental results, reported iodine leaching rates vary by 4 orders of magnitude, from $10^{-1}$ and $10^{-5} \mathrm{~g} \mathrm{~m}^{-2} \mathrm{~d}^{-1}$, largely due to the differences in the sample compositions, test methods, test parameters, and sample synthesis methods. Therefore, citing an iodine release rate from an experiment should always include details of the sample composition, test method along with test conditions, and how the rate is calculated. For iodoapatite with different iodine species, e.g., iodide $v s$. iodate, the leaching kinetics is expected to be different. For iodoapatite with similar compositions, it is challenging to integrate those experimentally measured rates for the understanding of the iodine leaching mechanism because of different test conditions and test methods. Therefore, it is necessary to conduct a systematic study that provides mechanistic insight of the waste form durability and the radionuclide release behaviour.

During a static leaching experiment, dissolved species accumulate in the solution. An increase of the chemical potential of the dissolved species in solution leads to the decrease of free energy driving force (chemical affinity), resulting in a reduced dissolution rate (solution feedback) if the dissolution is solubility-controlled. The rate at which species build up in solution during a static leaching experiment is dependent on the $\mathrm{S} / \mathrm{V}$ ratio. For dynamic leaching experiments, the build-up is dependent on flow rate and surface area of the sample in a continuous flow through experiment, and on the $\mathrm{S} /$
$\mathrm{V}$ ratio and exchange interval in a semi-dynamic leaching experiment. Therefore, it is not appropriate to directly compare the rates discussed above that were measured using different test methods or simply to infer the leaching mechanism based on such comparisons. Secondary phase formation also affects leaching rate that can be misinterpreted as incongruent release of iodine. ${ }^{17,21}$ It was speculated that ion exchange affects the iodine release, ${ }^{17,21}$ which, however, has not been quantified. A spectroscopic study of iodoapatite $\mathrm{Pb}_{5}\left(\mathrm{VO}_{4}\right)_{3} \mathrm{I}$ surfaces leached at $\mathrm{pH} 11$ in a $\mathrm{KOH} / \mathrm{KHCO}_{3}$ buffered solution at $90{ }^{\circ} \mathrm{C}$ for up to 8 weeks ${ }^{10}$ showed a $\mathrm{CO}_{3}{ }^{2-}$ Raman peak around $1058 \mathrm{~cm}^{-1}$ and $\mathrm{OH}^{-}$peak around $3538 \mathrm{~cm}^{-1}$, suggesting that the iodide $\mathrm{I}^{-}$ is replaced by $\mathrm{OH}^{-}$and $\mathrm{CO}_{3}{ }^{2-}$ through an ion exchange process. However, there is a strong $\mathrm{pH}$ dependence of dissolution of apatite at acidic and basic conditions, ${ }^{9,25-28}$ and most of the leaching experiments were conducted with deionized water at near-neutral $\mathrm{pH}$ where the dissolution rate is low and not sensitive to $\mathrm{pH}$ changes. Thus, it is necessary to investigate whether the iodide exchanges with $\mathrm{OH}^{-}$in deionized water and to what extent the ion exchange affects iodide release at nearneutral $\mathrm{pH}$ when the $\mathrm{OH}^{-}$concentration is low.

The focus of this study is to understand the dissolution mechanism of iodoapatite pellets based on the measured solution concentrations, model fitting, and surface microscopic and spectroscopic characterizations. Iodoapatite is a single phase material in which the iodine is stoichiometrically incorporated in a crystallographic site. Our hypothesis is that, due to different bonding environments in the structure (i.e., the more ionic bonding of the iodide and more covalent bonding of the framework $\mathrm{Pb}, \mathrm{V}$, and $\mathrm{O}$ ), the weakly ionically bonded iodide ion can be preferentially released by ion exchange with $\mathrm{OH}^{-}$while the framework structure dissolves. A semi-dynamic test method was used to distinguish between dissolution-controlled and diffusion-controlled release processes. The results provide an improved understanding of how the iodine release is controlled by different processes that include dissolution and diffusion, the latter involves ion exchange of iodide and hydroxide.

\section{Experiment}

\section{Materials}

The iodoapatite samples were prepared using high energy ball milling (HEBM) and spark plasma sintering (SPS) techniques. Dense ceramic pellets 14 millimetre in diameter and 2 millimetre in thickness were synthesized previously ${ }^{16}$ with a chemical composition of $\mathrm{Pb}_{9.85}\left(\mathrm{VO}_{4}\right)_{6} \mathrm{I}_{1.7}$ according to the EDS and $\mathrm{X}$ ray diffraction refinement. The samples may contain small amounts of $\mathrm{PbI}_{2}$ and $\mathrm{Pb}_{3}\left(\mathrm{VO}_{4}\right)_{2}$ as residual phases that were not detectable by X-ray diffraction. The samples have an apparent density of $\sim 96 \%$ of the theoretical value with small pores submicrometer in size. The details of the synthesis and characterization were reported in a previous publication and are only summarized here for completeness. ${ }^{16}$ Sample surfaces were successively polished by a mechanical polishing wheel using 600,2400 , and 4000-grit papers with ethanol lubrication and were thoroughly rinsed using ethanol and air dried before they 
were used in a leaching experiment. Two sample pellets were used for the leaching experiment to test the reproducibility.

\section{Leaching protocol and elemental analysis}

The leaching experiment was based on an accelerated leaching method, ${ }^{29}$ which provides a procedure for measuring the leaching rates of elements from a solid material. The method follows a semi-dynamic dissolution procedure in which the sample is immersed in a leachant for a given time interval and the leachate is periodically replaced with new leachant after each interval (Fig. 1). Based on the elemental analysis of successively collected leachates, the results can be quantified to characterize the release mechanisms. The method implements elevated temperatures to accelerate the leaching to an extent that would need to be achieved over considerably longer time at ambient temperature.

The experiments were conducted in cap-sealed Teflon vessels (Savillex) in a digitally controlled oven at a constant temperature of $90 \pm 0.5^{\circ} \mathrm{C}$ using deionized water as the leachant. The apatite pellet was placed on a mesh stand in a Teflon vessel $(30 \mathrm{~mL})$, which was filled with deionized water to provide an $\mathrm{S} / \mathrm{V}$ ratio of $16 \mathrm{~m}^{-1}$. The $\mathrm{S} / \mathrm{V}$ ratio is considered to remain constant during the experiment as the leached fraction of the sample is very small $\left(\sim 2 \times 10^{-5}\right)$. The leachant replacement intervals were 2,5 , and 17 hours for the first three intervals and 24 hours thereafter based on the test protocol. ${ }^{29}$ Due to large uncertainty of the data, the first three data points (first day) are not used for analysis and were excluded from the cumulative concentration. The vessels were weighed before and after each interval to monitor the solution weight loss. The loss of weight was mainly due to the cap seal of the Teflon vessel. Tests were performed on tightening the cap. All the experiments had a solution loss within $1 \%$ of the initial solution mass. In addition, to check if there are any deposits on the wall of the vessels, acid strip tests were applied to the vessels upon the termination of the leaching experiments. The elemental analysis on the strip solutions

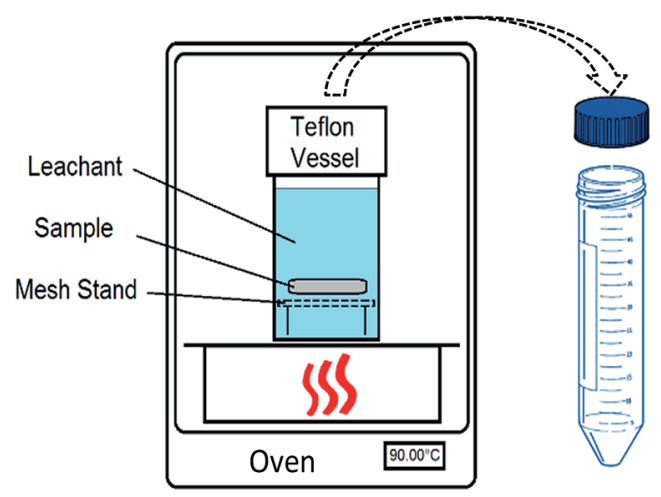

Fig. 1 Schematic of the experiment method, a semi-dynamic dissolution procedure, in which the sample is immersed in leachant for a given interval (e.g., 1 day), and the solution is completely replaced with new leachant periodically. Successive leachates are collected upon each interval and the elemental analysis was performed by ICPMS. confirmed the sorption of leached elements on vessel is negligible.

The leachate was analysed with a PerkinElmer Elan 9000 Inductively Coupled Plasma-Mass Spectrometry (ICP-MS) system. Internal standards cesium (Cs), manganese (Mn), and bismuth (Bi) were utilized in the analysis of iodine (I), vanadium $(\mathrm{V})$, and lead $(\mathrm{Pb})$ in leachate, respectively. Three standard solutions provided by Inorganic Ventures were used in ICP-MS calibration and analysis: (i) an iodine standard containing $1.001 \pm 0.007 \mu \mathrm{g} \mathrm{mL}{ }^{-1}$ iodide in $\mathrm{H}_{2} \mathrm{O}$ solution, (ii) a lead and vanadium standard containing $1.000 \pm 0.007 \mu \mathrm{g} \mathrm{mL}{ }^{-1} \mathrm{~Pb}$ and $1.000 \pm 0.006 \mu \mathrm{g} \mathrm{mL}^{-1} \mathrm{~V}$ in $1 \% \mathrm{HNO}_{3}$ solution respectively, and (iii) an internal standard containing $1.000 \pm 0.009 \mu \mathrm{g} \mathrm{mL}^{-1} \mathrm{Cs}$, $1.000 \pm 0.008 \mu \mathrm{g} \mathrm{mL}^{-1} \mathrm{Mn}$, and $1.000 \pm 0.006 \mu \mathrm{g} \mathrm{mL}{ }^{-1} \mathrm{Bi}$ in $2 \%$ $\mathrm{HNO}_{3}$. For a typical leachate analysis, a $1 \mathrm{~mL}$ internal standard was added into a $14 \mathrm{~mL}$ leachate solution (often diluted). The overall error of measured concentration is estimated to be around $20 \%$ depending on the concentration, propagated from ICP-MS analysis, dilution of the leachate before analysis, geometric surface area estimation, leachant weight loss during experiment, and oven temperature control, among others.

\section{Sample characterization}

Apatite sample surfaces were characterized by X-ray diffraction (XRD), scanning electron microscopy (SEM) and infrared spectroscopy. The sample pellets were rinsed thoroughly with ethanol and dried in air right after the leaching test before the characterizations. XRD analysis was conducted on the surfaces of the sample pellets before and after the leaching test, using PANalytical Empyrean multipurpose diffractometer with $\mathrm{Cu} \mathrm{K}$ $\alpha 1$ (0.154056 $\mathrm{nm}$ wavelength) at room temperature. The result is plotted in Fig. 2 along with the XRD pattern of iodoapatite with the same composition from ICDD database. ${ }^{30}$ The diffractometer was calibrated with standards before the analysis. For the samples before the test, the XRD pattern shows almost pure iodoapatite, consistent with the pattern in the literature. ${ }^{16} \mathrm{~A}$

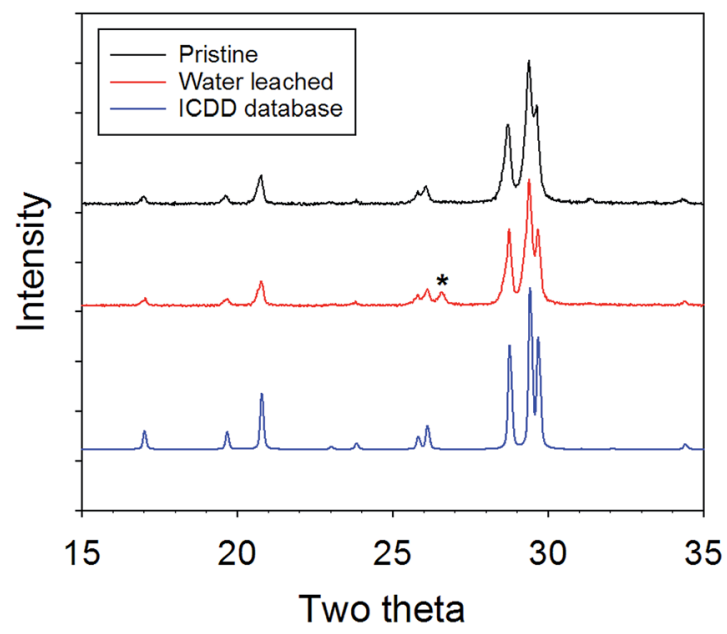

Fig. 2 X-ray diffraction patterns of the surfaces of the pristine and

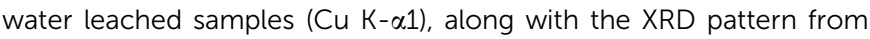
ICDD database for comparison. 
peak at about $26.5^{\circ}$ two theta, marked as star in Fig. 1, is from graphite, a residual material from the sample chamber material during SPS synthesis. The peak was not always observed because the residual in the pellets is not homogeneous. After the leaching test, the XRD pattern is almost identical to the original sample. SEM analysis was performed on the sample pellets before and after the leaching test, using a FEI Quanta SEM system with FEI Versa 3D DualBeam. The SEM images were taken on the pellets of the samples without surface coatings at room temperature. Infrared spectroscopic analysis was performed on the samples with the Thermo Nicolet Continuum Infrared Microscope with an aperture area of $10 \mu \mathrm{m}$ by $10 \mu \mathrm{m}$ and covering 4000 to $600 \mathrm{~cm}^{-1}$ range at a spectral resolution of $2 \mathrm{~cm}^{-1}$. The IR spectra were taken on the surfaces of the pellets in reflection mode, and the small particles from the pellet surfaces in transmission mode at room temperature. The spectra collected in the two modes are consistent.

\section{Results and discussion}

\section{Leaching of iodoapatite}

The cumulative concentration of the individual elements released from iodoapatite indicates that the iodine release has a different time dependence than the releases of lead and vanadium. Fig. 3 shows a complex relation between cumulative concentrations (millimole per $\mathrm{m}^{2}$ ) and test time. For iodine, the curves in Fig. 3a from the two experiments are similar, but
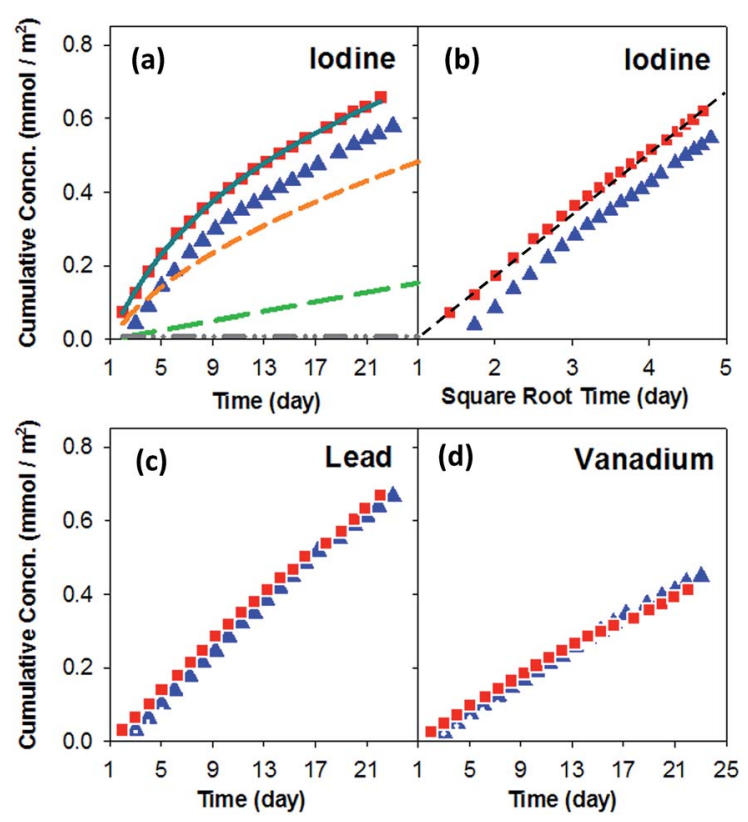

Fig. 3 Cumulative release of elements in leachate solutions normalized to the sample surface area (millimole per $\mathrm{m}^{2}$ ). The first three data points (first day) are excluded in the cumulative concentration. Red and blue symbols are the two experiments. (a) lodine. Lines are fitting results: solid light blue line - total; dashed orange - diffusion; dashed green - dissolution; dot-dot-dashed grey - surface effect. $R$ square value of fitting: 0.99. (b) lodine vs. square root of time. Dashed line is as guide to the eye. (c) Lead. (d) Vanadium. Error bars from ICP-MS measurement are within the symbols. neither fully resembles a straight line or a parabolic curvature. Likewise, the trends in Fig. 3b differ from a straight line (the dashed line is included to show the deviation between the straight line and data points). A parabolic curvature in Fig. 3a or a straight line in Fig. 3b would suggest a diffusion controlled release mechanism of the mobile species from an inert matrix. Quantification of the cumulative concentration as a function of time is necessary to understand iodine leaching behaviour. The lines in Fig. 3a show a regression of one dataset to the empirical model of Cote, ${ }^{31}$ which uses three separate terms to represent diffusional and linear dissolution behaviour and surface artefacts as given in eqn (1):

$$
\text { Cumulative }(t)=k_{1} t^{1 / 2}+k_{2} t+k_{3}\left(1-\mathrm{e}^{-k_{4} t}\right)
$$

in which, the cumulative amount of the element of interest in solution is described by the coefficient of diffusive character $k_{1}$, the coefficient of constant dissolution character $k_{2}$, and coefficients of surface effect $k_{3}$ and $k_{4}$. In Fig. 3a, the short-dashed (gold) curve represents the diffusional component, the longdashed (green) line the linear component, and the dot-dotdashed (grey) curve the surface artefact component of the cumulative measured concentration. The sum of these contributions is shown by the solid-line (turquoise) and represents the iodine data well. Following the procedure to describe the diffusion thickness in the literature, ${ }^{22}$ the diffusion coefficient, which is related to $k_{1}$ in eqn (1), was calculated to be $9 \times$ $10^{-21} \mathrm{~m}^{2} \mathrm{~s}^{-1}$. The value is about 2 orders of magnitude higher than the reported value $\left(4.5 \times 10^{-23} \mathrm{~m}^{2} \mathrm{~s}^{-1}\right)$ in a previous leaching test with a slightly different composition. ${ }^{22}$ The diffusion coefficients are expected to be different because the previous experiment was conducted in a static condition over more than 1000 days and the present experiment employed a semi-dynamic protocol with daily leachant replacement. The diffusion coefficient is dependent on test method and test conditions.

Comparing to the iodine release, the lead and vanadium releases are more or less linear with time (Fig. 3c and d), suggesting a constant dissolution controlled mechanism at a rate that is independent of time. Note that variations in the test intervals between 16 and 19 days in both tests are experimental artefacts that introduced a shift in the trends, but the data points before and after are linear with time.

The iodine release rate after three weeks of test is $\sim 0.18 \mathrm{mmol} \mathrm{m}^{-2} \mathrm{~d}^{-1}$ or $2.3 \times 10^{-3} \mathrm{~g} \mathrm{~m}^{-2} \mathrm{~d}^{-1}$, calculated from the slope of Fig. 3a at 21 day, which is similar to the leaching rate $\left(2.5 \times 10^{-3} \mathrm{~g} \mathrm{~m}^{-2} \mathrm{~d}^{-1}\right)$ reported in a flow through experiment with similar composition $\left(\mathrm{Pb}_{10}\left(\mathrm{VO}_{4}\right)_{4.8}\left(\mathrm{PO}_{4}\right)_{1.2} \mathrm{I}_{2}\right){ }^{20}$ As both the experiments were conducted using dynamic protocols, the similar leaching behaviour is expected and the effect of slightly different compositions seems limited. In contrast, our measured rate is about one order of magnitude higher than the rate $\left(2 \times 10^{-4} \mathrm{~g} \quad \mathrm{~m}^{-2} \mathrm{~d}^{-1}\right)$ reported for iodoapatite $\left(\mathrm{Pb}_{10}\left(\mathrm{VO}_{4}\right)_{4.8}\left(\mathrm{PO}_{4}\right)_{1.2} \mathrm{I}_{2}\right)$ using a static protocol after more than 1000 days of test. ${ }^{22}$ For static leaching experiment using a iodate apatite $\left(\mathrm{Ca}_{10}\left(\mathrm{PO}_{4}\right)_{6}\left(\mathrm{IO}_{3}\right)_{0.92}(\mathrm{OH})_{1.08}\right)$, the measured iodine release rate decreased about 2 orders of magnitude from initial 
release to residual release. ${ }^{17}$ Although the speciation of iodine and composition of iodoapatite have an important effect on iodine release rate, the dramatic differences in the rates for a given composition are primarily due to the different test methods (i.e., static tests give averaged cumulative rates and dynamic tests give instantaneous rates), various test parameters (e.g., S/V ratio, temperature), and how the rate is calculated (e.g., initial $v s$. residual). The results cannot be directly compared because the rates measured in static, dynamic, and semidynamic test methods have different meanings and depend on the dissolution mechanism.

In a dynamic test experiment, steady-state conditions may be attained between the flow rate and the dissolution rate for an affinity-controlled mechanism. The rate that is derived will depend on the steady-state solution composition under the particular test conditions and will represent an instantaneous rate. The rates measured in static tests are based on the accumulated concentrations of dissolved species and represent average rates over the test duration. In a static experiment, however, the solution feedback effect (affinity effect) increases over time, leading to the increased saturation with respect to the solid and reduced dissolution rate. The semi-dynamic tests described in this paper provide the average rates for a series of short intervals. The change in the rate over successive intervals gives insight into the dissolution mechanism. Constant rates measured over sequential intervals indicate a surface dissolution mechanism, whereas decreasing rates may indicate a diffusion-controlled mechanism. The rate measured for an interval will depend on the test conditions and time of the interval. The physical significances of the test results are different for diffusion-controlled processes, where time is the important variable. The semi-dynamic method was designed to study diffusion-controlled processes, for which static and dynamic methods are not effective. Therefore, the leaching rates measured by using different methods like static test cannot be directly compared with the results from flow through or semi-dynamic experiments. ${ }^{6,9,17,21,22}$ However, measurements of the leaching behaviour using different test protocols are necessary as they provide different aspects of the durability under different environmental conditions.

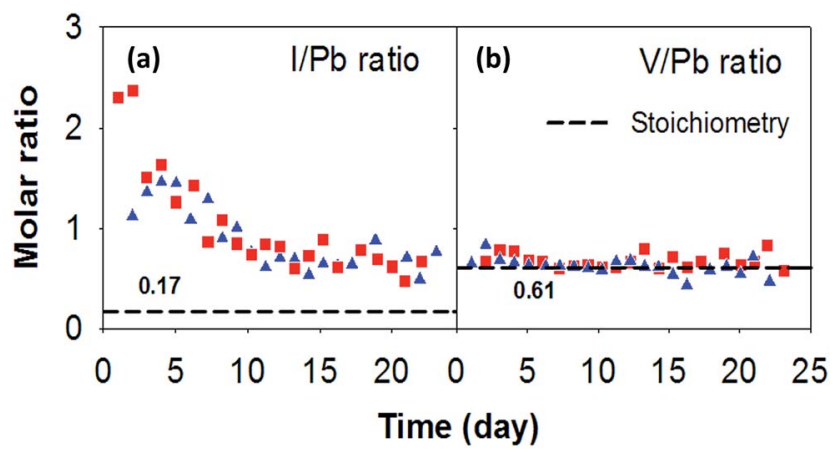

Fig. 4 Molar ratios of I/Pb (a) and V/Pb (b) as a function of leaching time. The horizontal dashed lines are stoichiometric ratio of the elements. Red and blue symbols are the two experiments. Error bars from ICP-MS measurement are within the symbols.

\section{Leaching mechanism}

The molar ratios of the elements in solutions from sequential test intervals are shown in Fig. 4. The iodine-to-lead molar ratio is about 2.3 at the beginning of the experiment, which is nearly 14 times higher than the stoichiometric ratio (i.e., 0.17), but decreases to $\sim 2$ times of the stoichiometric value after about 10 days (Fig. 4a). The difference in $\mathrm{I} / \mathrm{Pb}$ molar ratios between the measured and the stoichiometric value indicates the release of iodine is incongruent with respect to $\mathrm{Pb}$. Similar iodine release behaviour was also observed in previous studies of iodoapatite dissolution. ${ }^{9,17}$ In contrast, the vanadium-to-lead molar ratio is constant over time within errors, suggesting congruent dissolution of the two elements (Fig. 4b). Although the estimated error of the ratio (28\%), propagated from the error of the concentrations $(20 \%)$, is large, the trends in both Fig. 4 a and $\mathrm{b}$ are clear. In addition, thermodynamic calculations using MINTEQ $^{32}$ suggest that the leachate solutions were undersaturated with low solubility solid phases including $\mathrm{Pb}_{3}\left(\mathrm{VO}_{4}\right)_{2}$, which has a similar $\mathrm{V} / \mathrm{Pb}$ ratio $(0.67)$ to the iodoapatite. The incongruent release behaviours of iodine, lead, and vanadium is consistent with their being released from different chemical bonding environments, where iodide is released from more ionic bonds at channel anion site and lead and vanadium are released from more covalent bonds in the apatite structure. ${ }^{\mathbf{1 9}}$

As suggested in the regression fitting of the Cote model (Fig. 3a), the enhanced iodide leaching with respect to lead and vanadium from the solid (Fig. 4) may originate from a diffusioncontrolled process in which iodide $\left(\mathrm{I}^{-}\right)$in the solid is replaced by hydroxide $\left(\mathrm{OH}^{-}\right)$from the solution. Such a process is common for ions that are weakly bonded to a covalently bonded matrix structure such as in zeolites and clay minerals. ${ }^{33-37}$

The $\mathrm{pH}$ change of the leachate during leaching tests has been used as an indicator of ion exchange process between iodide or iodate in iodoapatite and hydroxide in solution in two previous experiments. ${ }^{17,22}$ The ion exchange reaction decreases the solution $\mathrm{pH}$ because the exchange reaction consumes hydroxide in the solution. Both of the experiments ${ }^{17,22}$ were performed using a static protocol with high surface to volume ratios (3000 $\mathrm{m}^{-1}$ and $8000 \mathrm{~m}^{-1}$ respectively). The accumulated ion exchange over the many days of the tests with limited iodoapatite dissolution under close to the saturated condition leads to a clear trend of $\mathrm{pH}$ decrease. However, a trend of $\mathrm{pH}$ change was not observed in our leaching tests because our leaching experiment is semi-dynamic and the leachate solutions are not accumulative. The average leachant (DI water) $\mathrm{pH}$ measured in our experiment was $5.3 \pm 0.2$ and the average leachate $\mathrm{pH}$ was $5.2 \pm 0.2$. A similar $\mathrm{pH}$ behaviour without a significant change of $\mathrm{pH}$ was also observed in a dynamic leaching test using a flow through protocol with a slight different composition $\left(\mathrm{Ca}_{10}\left(\mathrm{PO}_{4}\right)_{6}\left(\mathrm{IO}_{3}\right)_{0.92}(\mathrm{OH})_{1.08}\right){ }^{20}$ In fact, the measured $\mathrm{pH}$ values in our experiment are not reliable and don't reflect the $\mathrm{pH}$ in the Teflon vessel during the test because the solution is too dilute and was exposed to the air during the storage and $\mathrm{pH}$ measurement. Instead, thermodynamic calculations were performed to estimate $\mathrm{pH}$ change using MINTEQ and measured concentrations of the species in the solution. An 

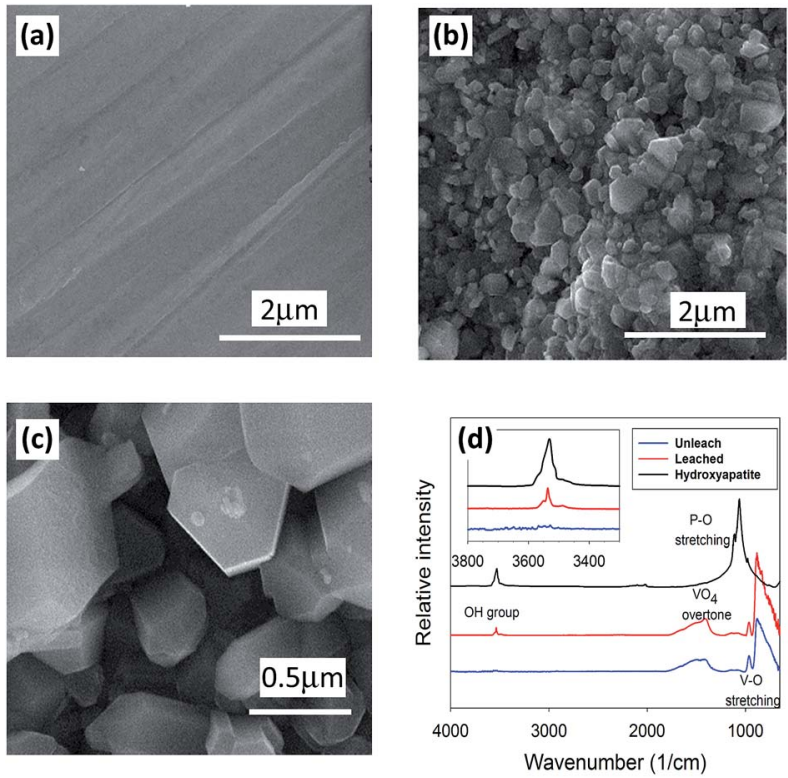

Fig. 5 SEM images of iodoapatite surfaces: fresh polished (a), surface leached with deionized water (b), a close-up (c), and IR spectra collected in transmission mode of unleached and leached iodoapatite and a hydroxyapatite from ref. 10 (d).

average increase of $\mathrm{pH}$ by 0.15 was predicted at beginning of the test and 0.05 at near the end of the test. ${ }^{32}$ Due to the test protocol (semi-dynamic and daily replacement of the leachant) and a small surface to volume ratio $16 \mathrm{~m}^{-1}$, there were two processes in our leaching test: ion exchange, which causes the solution $\mathrm{pH}$ to decrease; and dissolution of the iodoapatite, which causes the $\mathrm{pH}$ to increase. As a result of the two processes and small progresses of the reactions within a day, the $\mathrm{pH}$ increases slightly but the change was too small to be detected. An increase of $\mathrm{pH}$ was observed in the initial test period of a static leaching experiment with similar the iodine release mechanism. ${ }^{\mathbf{1 7}}$

The enhanced release resulting from the exchange of $\mathrm{I}^{-}$and $\mathrm{OH}^{-}$is expected to produce surface features that could be detected with spectroscopic and microscopic techniques. Fresh polished and leached surfaces are shown in Fig. 5a-c. No secondary phases are present at the surfaces from the SEM images from the secondary electron (Fig. 5b and c) and backscattered electron images. The IR spectrum of a leached sample (red) shows absorption peaks from $3450-3600 \mathrm{~cm}^{-1}$ with a sharp absorption peak around $3537 \mathrm{~cm}^{-1}$ (Fig. 5d), which are absent in the spectrum of the unleached sample (blue). These peaks are assigned to $\mathrm{OH}^{-}$in the channel site of the iodoapatite, which was occupied by iodide ion before the test and replaced by $\mathrm{OH}^{-}$as a result of ion exchange during the test. This result is consistent with the previous observation of both $\mathrm{CO}_{3}{ }^{2-}$ and $\mathrm{OH}^{-}$Raman peaks on the surface of iodoapatite that had been leached in a $\mathrm{KOH} / \mathrm{KHCO}_{3}$ buffered solution of $\mathrm{pH} 11 .^{10}$ Our results show that the ion exchange can also occur under neutral conditions despite of the strong $\mathrm{pH}$ dependence of iodoapatite dissolution. ${ }^{9}$

\section{Summary and conclusions}

Leaching experiments were conducted with dense ceramic single-phase lead vanadium iodoapatite monolith pellets using a semi-dynamic leaching method. Elemental analysis of the leachates suggests that iodide is initially released by ion exchange of iodide $\left(\mathrm{I}^{-}\right)$with hydroxide $\left(\mathrm{OH}^{-}\right)$in solution at rates that are controlled by diffusion while lead and vanadium are released at a constant dissolution rate. The preferential release of iodide with respect to lead gradually reduced from about $14: 1$ to about $2: 1$ over time as $\mathrm{I}^{-}$was depleted from the specimen surface. Microscopic and spectroscopic analyses of the leached samples are consistent with the proposed mechanism. Experiments conducted using methods that distinguish between mechanistic processes and various test parameters representing the range of environmental conditions are needed to fully understand the dissolution behaviour of iodoapatite and predict the long-term release of iodine.

\section{Conflicts of interest}

There are no conflicts to declare.

\section{Acknowledgements}

This work was supported as part of the Center for Performance and Design of Nuclear Waste Forms and Containers, an Energy Frontier Research Center funded by the U.S. Department of Energy, Office of Science, Basic Energy Sciences under Award DE-SC0016584. We also acknowledge the Shared Instrumentation Facilities (SIF) and Center for Advanced Microstructures and Devices (CAMD) at LSU for characterization.

\section{Notes and references}

1 W. J. Weber, A. Navrotsky, S. Stefanovsky, E. R. Vance and E. Vernaz, MRS Bull., 2009, 34, 46-53.

2 J. D. Vienna, Int. J. Appl. Glass Sci., 2010, 1, 309-321.

3 B. J. Riley, M. J. Schweiger, D.-S. Kim, W. W. Lukens Jr, B. D. Williams, C. Iovin, C. P. Rodriguez, N. R. Overman, M. E. Bowden, D. R. Dixon, J. V. Crum, J. S. McCloy and A. A. Kruger, J. Nucl. Mater., 2014, 452, 178-188.

4 D. A. McKeown, I. S. Muller and I. L. Pegg, J. Nucl. Mater., 2015, 456, 182-191.

5 B. J. Riley, J. D. Vienna, D. M. Strachan, J. S. McCloy and J. L. Jerden Jr, J. Nucl. Mater., 2016, 470, 307-326.

6 F. Audubert, J. Carpena, J. L. Lacout and F. Tetard, Solid State Ionics, 1997, 95, 113-119.

7 J. Carpena, B. Donazzon, E. Céraulo and S. Prené, Comptes Rendus de L'Académie des Sciences. Série II. Fascicule c, Chimie, 2001, 4, 301-308.

8 M. Uno, M. Shinohara, K. Kurosaki and S. Yamanaka, J. Nucl. Mater., 2001, 294, 119-122.

9 C. Guy, F. Audubert, J.-E. Lartigue, C. Latrille, T. Advocat and C. Fillet, C. R. Phys., 2002, 3, 827-837.

10 M. Zhang, E. R. Maddrell, P. K. Abraitis and E. K. H. Salje, Mater. Sci. Eng., B, 2007, 137, 149-155. 
11 S. Le Gallet, L. Campayo, E. Courtois, S. Hoffmann, Y. Grin, F. Bernard and F. Bart, J. Nucl. Mater., 2010, 400, 251-256.

12 M. C. Stennett, I. J. Pinnock and N. C. Hyatt, J. Nucl. Mater., 2011, 414, 352-359.

13 L. Campayo, A. Grandjean, A. Coulon, R. Delorme, D. Vantelon and D. Laurencin, J. Mater. Chem., 2011, 21, 17609-17611.

14 S. A. T. Redfern, S. E. Smith and E. R. Maddrell, Mineral. Mag., 2012, 76, 997-1003.

15 F. Y. Lu, Z. L. Dong, J. M. Zhang, T. White, R. C. Ewing and J. Lian, RSC Adv., 2013, 3, 15178-15184.

16 T. Yao, F. Lu, H. Sun, J. Wang, R. C. Ewing and J. Lian, J. Am. Ceram. Soc., 2014, 97, 2409-2412.

17 A. Coulon, A. Grandjean, D. Laurencin, P. Jollivet, S. Rossignol and L. Campayo, J. Nucl. Mater., 2017, 484, 324-331.

18 C. Cao, S. Chong, L. Thirion, J. C. Mauro, J. S. McCloy and A. Goel, J. Mater. Chem. A, 2017, 5, 14331-14342.

19 M. E. Fleet, Carbonated hydroxyapatite: materials, synthesis, and applications, CRC Press, 2014.

20 F. Audubert and J.-E. Lartigue, Conférence Internationale ATALANTE 2000, 2000, Paper P4.13.

21 Y. Suetsugu, J. Nucl. Mater., 2014, 454, 223-229.

22 L. Campayo, F. Audubert, J.-E. Lartigue, E. Courtois-Manara, S. Le Gallet, F. Bernard, T. Lemesle, F. O. Mear, L. Montagne, A. Coulon, D. Laurencin, A. Grandjean and S. Rossignol, Mater. Res. Soc. Symp. Proc., 2015, 1744, 15-20.

23 D. Strachan, R. Turcotte and B. Barnes, Nucl. Technol., 1982, 56, 306-309.

24 ASTM-C1220-10, International Standard Test Method for Static Leaching of Monolithic Waste Forms for Disposal of Radioactive
Waste, ASTM International, West Conshohocken, PA, United States, 2010.

25 C. Chaïrat, J. Schott, E. H. Oelkers, J.-E. Lartigue and N. Harouiya, Geochim. Cosmochim. Acta, 2007, 71, 59015912.

26 N. Harouiya, C. Chaïrat, S. J. Köhler, R. Gout and E. H. Oelkers, Chem. Geol., 2007, 244, 554-568.

27 E. Valsami-Jones, K. Ragnarsdottir, A. Putnis, D. Bosbach, A. Kemp and G. Cressey, Chem. Geol., 1998, 151, 215-233.

28 M. W. Guidry and F. T. Mackenzie, Geochim. Cosmochim. Acta, 2003, 67, 2949-2963.

29 ASTM-C1308-08, Accelerated Leach Test for Diffusive Releases from Solidified Waste and a Computer Program to Model Diffusive, Fractional Leaching from Cylindrical Waste Forms, ASTM International, West Conshohocken, PA, 2009.

30 ICDD, Powder Diffraction File Inorganic and Organic Data Book, WILEY-VCH Verlag, 2010.

31 P. L. Côtê, T. W. Constable and A. Moreira, Nucl. Chem. Waste Manage., 1987, 7, 129-139.

32 S. R. Peterson, MINTEQ user's manual, Division of Waste Management, Office of Nuclear Material Safety and Safeguards, U.S. Nuclear Regulatory Commission, Washington, DC, 1987.

33 C. E. Harland, Ion exchange: theory and practice, Royal Society of Chemistry, 1994.

34 S. Miyata, Clays Clay Miner., 1983, 31, 305-311.

35 F. G. Helfferich, Ion exchange, Courier Corporation, 1962.

36 C. Colella, Miner. Deposita, 1996, 31, 554-562.

37 L. Curković, Š. Cerjan-Stefanović and T. Filipan, Water Res., 1997, 31, 1379-1382. 